\title{
Evaluation of the Amplicor Chlamydia trachomatis test versus culture in genital samples in various prevalence populations
}

\author{
B de Barbeyrac, I Pellet, B Dutilh, C Bébéar, B Dumon, M Géniaux, Ch Bébéar
}

\begin{abstract}
Objective-To evaluate a newly developed polymerase chain reaction (PCR) assay, Amplicor $C$ trachomatis for the detection of $C$ trachomatis in genital samples using cell culture for comparison.

Subjects-501 patients (431 women and 70 men) attending an STD clinic in Hôpital Pellegrin (high-risk population) and gynaecological clinics (low-risk population) in Bordeaux, France.

Methods-The genital samples (cervical and urethral) were tested for the presence of $C$ trachomatis using the Amplicor test and using standard cell culture identified by the immunofluorescence test using a monoclonal antibody to $C$ trachomatis. Discrepancies between the results of culture and Amplicor were further analysed by major outer membrane protein gene (omp1)-PCR of the specimens taken in transport media and by direct fluorescent antibody (DFA) staining of elementary bodies in culture transport tubes.
\end{abstract}

Results-After analysis of discrepancies, the revised sensitivity and specificity of PCR were $95 \cdot 3 \%$ and $100 \%$ and the positive and negative predictive values were $100 \%$ and $99.5 \%$, respectively.

Conclusion-The present results indicate that the Amplicor assay is rapid, specific and more sensitive than the culture method. This test provides an excellent non-culture method for the detection of $C$ trachomatis in various prevalence populations.

(Genitourin Med 1994;70:162-166)

\section{Introduction}

Chlamydia trachomatis, an obligate intracellular bacterium, is a common sexually transmitted disease-causing organism. The lack of evident symptoms contributes to the further spread of the disease and the most significant consequences of chlamydial infection for women include the increased risk of pelvic inflammatory disease, tubal infertility and ectopic pregnancy. ${ }^{1}$

Therefore, it is important to have a reliable diagnostic test. Cell culture is considered the reference method for detection of $C$ trachomatis in spite of less than $100 \%$ sensitivity. It is, however, labour intensive and requires two to three days for results. Tests using direct immunofluorescence, enzyme immunoassays and DNA probe techniques ${ }^{2}$ have been developed but some lack good sensitivity compared with cell culture. ${ }^{3}$ Nucleic acid amplification methods such as polymerase chain reaction (PCR) have the potential to provide specificities equal to that of culture and with higher sensitivity. Recently, there have been several reports of the use of PCR for the diagnosis of chlamydial urogenital infections. ${ }^{4-9}$ Two factors limiting the application of PCR techniques are the lack of standardisation and the lack of a simple method for amplification detection.

Roche Molecular Systems (RMS, Branchburg, NJ) has developed a standardised commercial chlamydia in vitro diagnosis assay, Amplicor ${ }^{T M} C$ trachomatis test, using DNA amplification (PCR) of the cryptic plasmid and an enzyme oligoassay for the colorimetric detection. ${ }^{10}$ Described here is the evaluation of the new Amplicor $C$ trachomatis test as compared with standard cell culture in high- and low-risk populations. Discrepant results were further analysed using direct immunofluorescence and a second PCR with primer set derived from a distinct genetic region.

\section{Methods}

Patient populations and specimen collection

Genital samples were collected at two sites in Bordeaux, France. At site A, specimens were collected from a low-risk population attending several gynaecological clinics. At site B, specimens were collected from a high-risk population attending the outpatient clinic for sexually transmitted diseases of the Hôpital Pellegrin.

A total of 501 samples were collected from 431 women and 70 men in sites A (349) and B (152) from September 1992 to March 1993. Three swabs were collected from each patient, one for Neisseria gonorrhoeae culture and the two others were for $C$ trachomatis culture and Amplicor. The collection order of the three swabs was randomised.

The swabs for culture were placed in a transport medium containing sucrose-phosphate buffer (2SP) with $2 \%$ fetal bovine serum without antibiotics. The specimens from site A were transported to a private medical laboratory (Laboratoire d'Analyses Médicales, rue Mandron, Bordeaux) and tested within 5 hours after collection. The specimens from site B were transported to the 
hospital laboratory and stored at $-70^{\circ} \mathrm{C}$ prior to processing (within three days).

The swabs for Amplicor from site $\mathrm{A}$ and site $B$ were placed into $1 \mathrm{ml}$ of specimen transport medium (Amplicor, RMS), transported to the hospital laboratory, stored at $+4^{\circ} \mathrm{C}$ prior to processing using the Amplicor test (within six days). Medical histories were taken for patients with discrepant results.

\section{Chlamydia culture}

At the private medical laboratory, cultures were performed with McCoy cells in 24-well microtitre plates. A single well was inoculated per specimen, with a single passage. At the hospital laboratory, each specimen was inoculated in duplicate onto McCoy cell monolayers on glass coverslips in vials and examined after one and two passages. Following centrifugation, the cultures were incubated for 48 hours at $37^{\circ} \mathrm{C}$ in the culture medium containing glucose and cycloheximide. After incubation, the plates and one coverslip were fixed and stained with fluorescein-labelled monoclonal antibodies directed against the major outer membrane protein (MOMP) (Microtrak, Syva, Palo Alto, CA). Plates and coverslips were then examined for inclusions. The cells on the remaining coverslip were removed and inoculated onto two fresh McCoy cell monolayers in vials. A specimen was considered positive if one or more inclusions were identified in either the initial or blind pass cultures. Strains from positive specimens were subcultured and conserved in 2SP medium at $-70^{\circ} \mathrm{C}$.

\section{Amplicor $C$ trachomatis test}

PCR amplification and detection of PCRamplified DNA (amplicons) were carried out according to the manufacturer's instructions. The Amplicor kits were kindly provided by Roche Molecular Systems France. Each specimen was tested in duplicate. Briefly, $1 \mathrm{ml}$ of specimen diluent (Amplicor, RMS) was added to the transport tube and mixed. An aliquot $(50 \mu \mathrm{l})$ of the specimen was mixed with $50 \mu \mathrm{l}$ of $2 \mathrm{x}$ PCR buffer (Amplicor, Master Mix, RMS) containing dATP, dCTP, dGTP, dUTP, biotinylated primers, AmpliTaq, using a micropipette with a plugged tip or positive displacement pipette. The Master Mix with AmpErase mixture was prepared in a dedicated area protected from the specimens and the amplicons aerosol. The remainder of the specimen was stored at $-20^{\circ} \mathrm{C}$. One amplification ready positive control and three amplification ready negative controls were included in each experiment. The sample tray was placed into a programmable model 9600 thermal cycler (Perkin-Elmer, Roche) for 30 cycles of denaturation at $95^{\circ} \mathrm{C}$ and hybridisation and annealing at $60^{\circ} \mathrm{C}$. Biotinylated amplicons were denatured by the addition of $100 \mu \mathrm{l}$ of $\mathrm{NaOH}$-based denaturation solution (Amplicor, RMS) in a dedicated area. A 25- $\mu \mathrm{l}$ aliquot of the denatured amplicon and $100 \mu \mathrm{l}$ of hybridization buffer were combined in a well of a 96-microwell plate that also contained an oligonucleotide "capture probe".
Hybridisation was carried out for one hour at $37^{\circ} \mathrm{C}$. Then microwells were washed with washing buffer and $100 \mu \mathrm{l}$ of avidin-horseradish peroxydase conjugate was added. Following 15 minutes of incubation at $37^{\circ} \mathrm{C}$ and after five washes, $100 \mu \mathrm{l}$ of substrate A/B (4 parts substrate $A$ to 1 part substrate $B$; Amplicor, RMS) was added. After incubation for 10 minutes in the dark at room temperature, $100 \mu$ l of stop solution (Amplicor, RMS) was added and the reaction was read in an automated microwell plate reader at $450 \mathrm{~nm}$. The cut-off between positive and negative result was an optical density (OD) of $0 \cdot 25$. A valid test consisted of negative controls with OD values less than 0.25 and a positive control with an OD greater than 2 .

\section{Analysis of discrepant results}

All specimens producing an Amplicor result discrepant with culture were amplified by using PCR primers CT1/CT2 directed against the $C$ trachomatis omp1 gene $^{11}$ on the two transport medium.

Different amplification protocols were used for each transport medium, 2SP or Amplicor specimen transport medium. For the specimens in the 2SP transport medium, lysis, DNA amplification and detection were performed following published procedures with some modifications. ${ }^{1112}$ Specimens were vortexed and $100 \mu \mathrm{l}$ was mixed with $200 \mu \mathrm{l}$ of lysis buffer [10 mM Tris-HCl, $1 \mathrm{mM}$ EDTA (pH $7 \cdot 5$ ), $0 \cdot 1 \%$ triton $\mathrm{X} 100,0.1 \mathrm{mg} / \mathrm{ml}$ proteinase $\mathrm{K}$ ] and heated at $55^{\circ} \mathrm{C}$ for 90 minutes and then for 30 minutes at $95^{\circ} \mathrm{C}$ to inactivate the proteinase $\mathrm{K}$. The amplification reaction was performed in a $50 \mu \mathrm{l}$-volume containing $10 \mu \mathrm{l}$ of this prepared sample, $10 \mathrm{mM}$ Tris$\mathrm{HCl}(\mathrm{pH} \mathrm{9.5),} 50 \mathrm{mM} \mathrm{KCl}, 0.1 \%$ triton $\mathrm{X} 100,1.5 \mathrm{mM} \mathrm{MgCl} 2,200 \mu \mathrm{M}$ (each) dATP, dTTP, dGTP and dCTP, $1 \mu \mathrm{M}$ of each primer and $2.5 \mathrm{U}$ of Taq DNA polymerase (Promega, Madison, WI). Three drops of mineral oil were added to prevent evaporation. The amplification was performed in a PCR thermocycler (Perkin-Elmer, Cetus) and each cycle contained a denaturation step at $94^{\circ} \mathrm{C}$ for 1 minute, a primer annealing step at $55^{\circ} \mathrm{C}$ for 1 minute and an elongation step at $72^{\circ} \mathrm{C}$ for 1 minute, for 35 cycles. The amplified samples were electrophoresed on a $8 \%$ polyacrylamide gel. For confirmation of the specificity of the PCR products, a restriction enzyme digestion by $E c o R I$ was used. The DNA fragments (77 and $52 \mathrm{bp}$ ) were separated by $8 \%$ polyacrylamide gel electrophoresis. DNA was visualised by ultraviolet fluorescence after staining with ethidium bromide.

The samples in Amplicor specimen transport medium, were transported to Roche Molecular Systems in Basel (Switzerland). The procedure was essentially identical to that used for amplification of the cryptic plasmid, except for the use of biotinylated omp1derived primers, and the use of a omp1 DNAspecific capture probe fixed to plate wells. For culture-positive and Amplicor-negative specimens, the Amplicor test was repeated on 
diluted specimens before concluding. A negative omp1-PCR result on specimens collected in the Amplicor specimen transport medium indicated the presence of a PCR inhibitor or a sampling error. A positive-omp1-PCR result on specimens collected in the 2SP transport medium indicated a culture true positive result. The isolated strains were tested with Amplicor test to verify the presence of the plasmid. The samples consisted of $10 \mu 1$ of the 2SP medium containing the strain, mixed with $1 \mathrm{ml}$ of Amplicor specimen transport medium.

For culture-negative and Amplicor-positive specimens, a positive-omp1-PCR result whatever the transport medium, confirmed the Amplicor-positive result and indicated a culture false-negative result. A negative-omp1PCR result indicated that the initial Amplicor result was a false positive result. In addition, a DFA test was performed on the 2SP transport medium. After centrifugation of the 2SP transport medium, $1 \mu \mathrm{l}$ of the resulting pellet was placed on a slide, fixed with methanol for five minutes and stained with $C$ trachomatis monoclonal antibodies (Syva, Microtrak) for the direct detection of elementary bodies (EBs). A specimen was considered positive if at least five EBs were identified. A summary of the protocol is given in table 1 .

\section{Statistical analysis}

A sample was considered true positive if either the cell culture was positive or if the cell culture being negative, both PCR tests, plasmid and $o m p 1$, were positive. A true negative sample was a sample for which the cell culture and the PCR tests were negative. However, a negative cell culture result in a treated patient was considered as true negative culture in spite of a positive Amplicor result. Sensitivity was calculated as the percentage of positive cell cultures or PCR tests among the true positive samples. Specificity was calculated as the percentage of negative cell cultures or PCR tests among the true negative samples.

Table 1 Flow chart of Chlamydia trachomatis detection

1-Specimen collection
1-1 two sites-site A, gynecological clinics
- site B, STD clinic
1-2 two swabs from 501 patients (349 site A, 152 site B), one
in $2 S P$ transport medium, one in specimen Amplicor
transport medium
2-Specimen analysis
2-1 C trachomatis culture in a private laboratory for specimens
from site A and in hospital laboratory for specimens from
site B
2-2 $C$ trachomatis Amplicor in hospital laboratory for all speci-
mens
3-Analysis of discrepant results
3-1 Amplicor+/culture -
-On Amplicor specimen transport medium
repeat Amplicor
omp1-PCR
-On 2SP transport medium
omp1-PCR
DFA test
3-2 Amplicor-/culture +
- On specimen Amplicor transport medium
repeat Amplicor on diluted specimen
omp1-PCR
-On 2SP transport medium
omp1-PCR

Positive and negative predictive values were calculated according to Bayes' rules ${ }^{14}$ by using the true prevalences calculated according to the criteria mentioned above.

\section{Results}

A total of 501 patients were evaluated for $C$ trachomatis using the Amplicor assay. Fortyone specimens were Amplicor positive and 460 were Amplicor negative. In three out of 27 experiments, the OD values of the positive control were lower than 2 and the tests had to be considered invalid. After a second test, the OD values of the positive control became greater than 2 and the outcome of the samples remained unchanged. When analysing the results of the specimens tested in duplicate, 491 pairs given concordant results, only 10 pairs yielded two borderline positive-negative PCR results. These samples were tested again and were considered negative. Concerning the culture method, 30 specimens were positive and all positive specimens were always detected in the initial culture.

The comparison of cell culture and Amplicor test results is shown in table 2 . Twenty eight specimens were Amplicor and culture positive, 458 specimens were negative in both tests, two were culture positive and Amplicor negative, and 13 were culture negative and Amplicor positive. Details of results of the different populations are shown in table 2. The Amplicor results of the 28 positive concordant specimens ranged from 0.3 to above 3 OD units. Of these, 27 yielded $O D$ values above 3 . In one case, the Amplicor assay was initially negative with an OD value below the cut off (repeated three times) and became positive with an OD value $>3$ after dilution of the sample. Therefore, the specimen was considered positive by both techniques. The specimens which were negative using culture and Amplicor yielded OD values of less than $0.25(0.06$ to 0.239$)$.

The prevalence of $C$ trachomatis as measured by positive cell culture was $5 \cdot 98 \%$ overall, $4 \%$ in site $A$ and $10.5 \%$ in site $B$ (table 3 ). On the basis of these data, the overall sensitivity of the Amplicor assay was $93.3 \%$, its specificity was $97 \cdot 2 \%$, its PPV was $68 \cdot 2 \%$ and its NPV was $99.5 \%$.

There were 15 discrepant results: 13 were

Table 2 Comparison of Amplicor test and cell culture results for $C$ trachomatis detection

\begin{tabular}{|c|c|c|}
\hline & \multicolumn{2}{|c|}{ No of samples using Amplicor test } \\
\hline & Positive & Negative \\
\hline $\begin{array}{c}\text { All patients }(n=501) \\
\text { Culture positive } \\
\text { Culture negative }\end{array}$ & ${ }_{13(8)^{\star}}$ & $\begin{array}{r}2 \\
458\end{array}$ \\
\hline $\begin{array}{l}\text { Site } A(n=349) \\
\text { Culture positive } \\
\text { Culture negative }\end{array}$ & 14 & $\begin{array}{r}0 \\
329\end{array}$ \\
\hline $\begin{array}{l}\text { Site } B(n=152) \\
\text { Culture positive } \\
\text { Culture negative }\end{array}$ & $\begin{array}{r}14 \\
7(5)^{\star}\end{array}$ & $\begin{array}{r}2 \\
129\end{array}$ \\
\hline
\end{tabular}

()$^{\star}$ number of antibiotic-treated patients 
positive by Amplicor and negative by culture with $O D$ values between 1.6 and $>3$, and two were positive by culture and negative by Amplicor. Of the 13 specimens which were Amplicor-positive and culture-negative, 13/13 were PCR positive in Amplicor specimen transport medium by the alternative omp1PCR and 9/11 in the 2SP transport medium, $3 / 10$ had five or more EBs in DFA of spun culture 2SP transport medium vials. In eight cases, the patients were treated for a suspected chlamydial infection. The details of these results are presented in table 4 . These 13 discrepant results must be considered as Amplicor true positive results. The prevalence of $C$ trachomatis as measured by the positive Amplicor assay was $8 \cdot 1 \%$ overall, $5.7 \%$ in site A and $13.8 \%$ in site B (table 3 ). The two Amplicor negative, culture-positive specimens, were reamplified from the Amplicor specimen transport medium using the Amplicor assay and the omp1-PCR and the results remained the same, even after dilution. In addition, the two specimens in the 2SP transport medium were positive by using omp 1-PCR and the two strains isolated from these specimens were

Table 3 Performance of Amplicor test and cell culture

\begin{tabular}{|c|c|c|c|c|c|}
\hline & \multirow[b]{2}{*}{ Prevalence } & \multirow[b]{2}{*}{ Sensitivity } & \multirow[b]{2}{*}{ Specificity } & \multicolumn{2}{|c|}{ Predictive value } \\
\hline & & & & Positive & Negative \\
\hline $\begin{array}{l}\text { All samples } \\
\text { Amplicor } \\
\text { Cell culture }\end{array}$ & $\begin{array}{l}8 \cdot 10 \% \\
5 \cdot 98 \%\end{array}$ & $\begin{array}{l}95 \cdot 3 \% \\
85 \cdot 7 \%\end{array}$ & $\begin{array}{l}100 \% \\
100 \%\end{array}$ & $\begin{array}{l}100 \% \\
100 \%\end{array}$ & $\begin{array}{l}99 \cdot 5 \% \\
98.9 \%\end{array}$ \\
\hline $\begin{array}{l}\text { Site } A \\
\quad \text { Amplicor } \\
\text { Cell culture }\end{array}$ & $\begin{array}{l}5 \cdot 7 \% \\
4 \%\end{array}$ & $\begin{array}{l}100 \% \\
82 \cdot 3 \%\end{array}$ & $\begin{array}{l}100 \% \\
100 \%\end{array}$ & $\begin{array}{l}100 \% \\
100 \%\end{array}$ & $\begin{array}{l}100 \% \\
99 \cdot 1 \%\end{array}$ \\
\hline $\begin{array}{l}\text { Site } B \\
\text { Amplicor } \\
\text { Cell culture }\end{array}$ & $\begin{array}{l}13 \cdot 8 \% \\
10 \cdot 5 \%\end{array}$ & $\begin{array}{l}91 \cdot 3 \% \\
87.5 \%\end{array}$ & $\begin{array}{l}100 \% \\
100 \%\end{array}$ & $\begin{array}{l}100 \% \\
100 \%\end{array}$ & $\begin{array}{l}\mathbf{9 8 . 4} \% \\
\mathbf{9 8 . 5} \%\end{array}$ \\
\hline
\end{tabular}

Table 4 Details of the 13 discrepant results, Amplicor +/Culture-

\begin{tabular}{lllll}
\hline & $\begin{array}{l}\text { omp1-PCR } \\
\text { (Amplicor specimen } \\
\text { No of sample }\end{array}$ & $\begin{array}{l}\text { omp1-PCR } \\
\text { transport medium) }\end{array}$ & $\begin{array}{l}\text { DFA } \\
(2 S P)\end{array}$ & $\begin{array}{l}\text { Antibiotic } \\
\text { treatment }\end{array}$ \\
\hline 1 & + & + & - & - \\
2 & + & ND $^{\star}$ & ND & + \\
3 & + & + & - & + \\
4 & + & ND & ND & + \\
5 & + & + & - & + \\
6 & + & + & ND & + \\
7 & + & + & + & + \\
8 & + & + & + & + \\
9 & + & + & + & + \\
10 & + & + & + & + \\
11 & + & + & & + \\
12 & + & + & + & + \\
13 & + & + & + & + \\
\hline
\end{tabular}

$\mathrm{ND}^{\star}$ : not done. positive by using Amplicor assay. These results indicated that the Amplicor test had failed and were considered to be false-negative Amplicor results. The comparison of cell culture and Amplicor test results after analysis of discrepant results is shown in table 5 . The adjusted sensitivity, specificity, PPV and NPV of the Amplicor assay increased to $95.3 \%$, $100 \%, 100 \%$ and $99.5 \%$, respectively (table 3 ). When analysing the results by sites, the sensitivity, specificity, PPV and NPV were $100 \%, 100 \%, 100 \%, 100 \%$ in site $\mathrm{A}$ and $91.3 \%, 100 \%, 100 \%, 98.4 \%$ in site $\mathrm{B}$, respectively. The sensitivity of cell culture for all the samples in this study compared with true positive samples was $85 \cdot 7 \%$.

\section{Discussion}

DNA amplification techniques are rapidly gaining importance in diagnostic microbiology, especially in detection of $C$ trachomatis because the sensitivity of the PCR technique is estimated to be higher than that of culture. However, several steps such as sample pretreatment, amplification parameters, analysis and control of specificity of PCR products are required to optimise PCR test results. Comparison of the performance of published PCR tests is difficult. An improvement has been achieved with the development of a standardised commercial PCR diagnosis-kit. The Amplicor $C$ trachomatis test involves a simple sample processing method, a rapid DNA amplification of the common $C$ trachomatis plasmid and a colorimetric microwell DNA hybridisation. We found the assay simple and quick to perform and in the vast majority of cases it gave very clear results, well above or below the cut-off level. Of the 41 Amplicor-positive specimens, only one yielded a borderline OD value of $0 \cdot 3$. This specimen contained only one inclusion in culture. Out of the $460 \mathrm{Amplicor}$-negative specimens, 450 yielded $O D$ values of less than $0 \cdot 25$. Only 10 specimens tested in duplicate gave discrepant results. These results show that it is not necessary to test the specimens in duplicate systematically, but all results, yielding a borderline OD value, have to be tested again.

In the present study, the Amplicor test had a sensitivity superior to that of culture after resolution of discrepant results. In processing 501 specimens, there were no false-positive PCR results. Although the Amplicor test failed to detect three culture-positive specimens, it identified 13 true-positive specimens that culture failed to detect. In the culture-positive Amplicor-negative cases, the explanation for this result could be either a false-positive cell culture, because of contamination or a falsenegative PCR test due to either PCR inhibitor or the presence of plasmidless strains or a sampling error. The fact that the alternative omp1-PCR tests were positive on culture transport medium, and on the two isolated strains, rules out the possibility that the cultures were false-positive and these isolates lacked the $C$ trachomatis cryptic plasmid. results after analysis of discrepant results

\begin{tabular}{lcc}
\hline & Amplicor & Culture \\
\hline True positive & 41 & 30 \\
True negative & 458 & $466^{\star}$ \\
False positive & 0 & 0 \\
False negative & 2 & 5 \\
\hline *Including eight treated patients & Amplicort/culture - .
\end{tabular}


The nature of the PCR inhibitors was not determined but in one case, after dilution of the specimen containing more than 20 inclusions per field, the Amplicor test became positive. It is possible that the presence of too much DNA matrix inhibits amplification. The question of the necessity to dilute all specimens before interpretation of results arises. Given that in this study, only one specimen in 501 required dilution, it is probably not necessary to dilute specimens routinely. Another possibility is that the two remaining false-negative Amplicor specimens resulted from swab to swab variability. The 13 culture-negative Amplicor-positive specimens were considered true-positive PCR results by using a second PCR assay with a different pair of primers. The use of two primer sets allows one to confirm these results. ${ }^{15}$ Ossewaarde ${ }^{6}$ suggested that the PCR with primers detecting at least two different specific chlamydial genes could be considered a new gold standard for laboratory use. A contamination is always possible but in our laboratory, we used separate areas for specimen processing, PCR set up, and product analysis to minimise carryover contamination. In addition, to avoid an aerosol contamination of a new clinical specimen with previously amplified DNA, the Amplicor $C$ trachomatis test incorporate the use of AmpErase $^{\mathrm{TM}}$ containing uracil-N-glycosylase (UNG).

The results of the PCR required careful interpretation, however, with additional data such as medical history and previous use of antibiotics. Indeed, after treatment, the samples remained PCR test positive while cell culture samples became negative, and remained so for at least three weeks without further treatment. ${ }^{913}$ The PCR test and also DFA test can detect non viable organisms and some authors have suggested that when the PCR test is used for test of cure, an interval of three weeks after treatment course is required. In the present study, out of 13 false-negative culture cases, eight may be explained by a tetracycline treatment. In the other five cases, the culture was falsely negative and its sensitivity was $85 \cdot 7 \%$. This result is higher than those of some published studies. In these studies, sensitivity of the culture method ranged from $65 \cdot 2 \%$ to $77 \cdot 5 \%{ }^{467}$ compared with PCR, but no clinical information was given. The advantage of PCR over culture for the eight patients who were suspected to be infected by $C$ trachomatis and treated as such, is that the results of the PCR affirmed the diagnosis of chlamydia infection.

Two studies, reporting the evaluation of the Amplicor $C$ trachomatis test in the USA, have been published. The first compared this test with culture in 503 cervical specimens and with Chlamydiazyme EIA in $375 . .^{\circ}$ The second compared it with culture of urethral swabs in 530 male urine samples. ${ }^{16}$ In cervical specimens, our results are similar showing a high sensitivity, superior to $95 \%$ and a specificity near to $100 \%$. In conclusion, these results show that the Amplicor $C$ trachomatis test is more sensitive than the cell culture method, whatever the population studied. This test is simple, rapid, highly specific and sensitive and can be used for the rapid diagnosis of $C$ trachomatis urogenital infections. It is certainly one of the best non-culture methods.

1 Taylor-Robinson D. Genital chlamydial infections: clinica aspects, diagnosis, treatment and prevention. In: Harri JRW, Forster SM (eds). Recent Advances in Sexually Transmitted Diseases and AIDS. Edinburgh, Churchil Livingstone, 1991:219-62.

2 Kluytmans JAJW, Niesters HGM, Mouton JW, et al. Performance of a nonisotopic DNa probe for detection of Chlamydia trachomatis in urogenital specimens. $\mathcal{F}$ Clin Microbiol 1991;29:2685-9.

3 Taylor-Robinson $\mathrm{D}$. The value of non-culture techniques for diagnosis of Chlamydia trachomatis infections: making the best of a bad job. Eur $\mathcal{F}$ Clin Microbiol Infect Dis 1992;11:499-503.

4 Näher H, Drzoneck $H$, Wolf J, von Knebel Doeberitz $M$ Petzoldt D. Detection of $C$ trachomatis in urogenital Petzoldt $\mathrm{D}$. Detection of $C$ trachomatis in urogenital specimens by poly

5 Williams TW, Tyler SD, Giercke S, Pollard DR, McNicol $P$, Rozee $K R$. Comparison of polymerase chain reaction and Chlamydiazyme for the detection of Chlamydia trachomatis in clinical specimens. Eur $\mathcal{f}$ Clin Microbio Infect Dis 1992;11:233-6.

6 Ossewaarde JM, Rieffe M, Rozenberg-Arska M Ossenkoppele PM, Nawrocki RP, van Loon AM Development and clinical evaluation of a polymerase chain reaction test for detection of Chlamydia trachomatis. f Clin Microbiol 1992;30:2122-8.

7 Wu C-H, Lee M-F, Yin S-C, Yang D-M, Cheng SF Comparison of polymerase chain reaction, monoclonal antibody based enzyme immunoassay, and cell culture for detection of Chlamydia trachomatis in genital specimens. Sex Transm Dis 1992;19:193-7.

8 mens. Sex Transm Dis 1992;19:193-7. $\mathrm{R}$ et al. Direct detection and genotyping of Chlamydia trachomatis in cervical scrapes by using polymerase chain reaction and restriction fragment length polymorphism anakysis. f Clin Microbiol 1993;31:1060-

9 Vogels WHM, van Voorst Vader PC, Schröder FP. Chlamydia trachomatis infection in a high risk population comparison of polymerase chain reaction and cell culture for diagnosis and follow-up. $₹$ Clin Microbiol 1993;31: 1103-7.

10 Loeffelholz MJ, Lewinski CA, Silver SR, et al. Detection of Chlamydia trachomatis in endocervical specimens by polymerase chain reaction. 7 Clin Microbiol 1992;30: 2847-51.

11 Dutilh B, Bébéar C, Rodriguez P, Vekris A, Bonnet J, Garret $M$. Specific amplification of a DNA sequence Garret $M$. Specific Res Microbiol 1989;140:7-16.

12 Griffais $R$, Thibon $M$. Detection of Chlamydia by the polymerase chain reaction. Res Microbiol 1989 140:139-41.

13 Claas HCJ, Wagenvoort JHT, Niesters HGM, Tio TT Van Rijsoort-Vos JH, Quint WGV. Diagnostic value of the polymerase chain reaction for Chlamydia trachomatis detection as determined in a follow-up study. $\mathcal{f}$ Clin Microbiol 1991;29:42-5.

14 Vecchio TY. Predictive value of a single diagnostic test in unselected populations. $N$ Engl F Med 1966;274:1171-3.

15 Mahony JB, Luinstra KE, Jang D, Sellors J, Chernesky MA. Chlamydia trachomatis confirmatory testing of PCR-positive genitourinary specimens using a second set of plasmid primers. Mol Cell Probes 1992;6:381-8.

16 Jaschek G, Gaydos CA, Welsh LE, Quinn TC. Direct detection of Chlamydia trachomatis in urine specimens detection of Chlamydia trachomatis in urine specimens from symptin rapid polymerase 